\title{
Assessment of coral bleaching using symbiotic zooxanthellae density and satellite remote sensing data in the Nansha Islands, South China Sea
}

\author{
LI Shu*, YU KeFu* ${ }^{*}$ CHEN TianRan, SHI Qi \& ZHANG HuiLing \\ CAS Key Laboratory of Marginal Sea Geology, South China Sea Institute of Oceanology, Chinese Academy of Sciences; Guangzhou 510301, China
}

Received October 19, 2010; accepted December 30, 2010

\begin{abstract}
Coral bleaching, characterized by a significant loss of symbiotic zooxanthellae, is the primary cause of mass coral mortality and reef degradation throughout the world. The characteristics, processes, and resistance of corals to bleaching varies significantly and is dependent on environmental conditions. We documented a mass coral bleaching event in June 2007 at the Meiji and Zhubi Reefs, Nansha Islands (NS), South China Sea using ecological surveys and measurement of coral zooxanthellae density and sea surface temperatures (SST). More than 35 species of corals (between 0-20 m in depth) were bleached. These bleached corals accounted for $15.6 \%$ of total corals in the investigated quadrats. The branching corals Pocillopora and Acropora were the most vulnerable species whereas the massive corals Porites and Favia were more tolerant of the high SSTs. Surprisingly, we found no evidence of bleaching in Agariciidae corals suggesting that this family is resistant to thermal stresses. The bleached corals had lost $72 \%-90 \%$ of their symbiotic zooxanthellae. Furthermore, corals that had no visual signs of bleaching had also lost $31 \%-53 \%$ of their zooxanthellae suggesting that most corals were experiencing the early stage of bleaching. The monthly mean SST during June 2007 was $30.8^{\circ} \mathrm{C}$, the highest since 1998. Based on measurements of SST and the Hotspots and DHW data (NOAA), we conclude that it the extremely high SSTs triggered this coral bleaching event. Our results suggest that the previously accepted temperature thresholds used to predict coral bleaching based on satellite data are likely to underestimate the extent and intensity of coral bleaching, at least in the NS.
\end{abstract}

coral bleaching, zooxanthellae density, anomalous SST, Nansha Islands, South China Sea

Citation: $\quad$ Li S, Yu K F, Chen T R, et al. Assessment of coral bleaching using symbiotic zooxanthellae density and satellite remote sensing data in the Nansha Islands, South China Sea. Chinese Sci Bull, 2011, 56: 1031-1037, doi: 10.1007/s11434-011-4390-6

Coral bleaching is an important marine ecological phenomenon. The process is characterized by the mass expulsion of symbiotic zooxanthellae caused by environmental stresses that include temperature extremes, high doses of ultraviolet light, disease, bacterial infection, and low salinity [1]. The recent, widespread occurrence of coral bleaching and subsequent reef degradation has generally been attributed to extremely high sea surface temperatures (SSTs) associated with ENSO (El Niño-Southern Oscillation) events and global warming [2,3]. For example, abnormal SSTs in the summer of 1998 caused coral bleaching in a number of

*Corresponding authors (email: lishucoral@gmail.com; yukefu@gmail.com) regions, resulting in the loss of $16 \%$ of the world's coral reefs [4]. Based on the projected impacts of global warming, nearly one-third of reef-building corals face an elevated risk of extinction [5], and only $46 \%$ of global coral reefs are currently classified as healthy [6].

The coral reefs in the south China Sea (SCS) cover an area of approximately $8000 \mathrm{~km}^{2}$ [7]. The largest concentration of these reefs occurs around the relatively remote Nansha Islands (NS). The reefs in this region play an important role in supporting marine biodiversity and other marine resources. Thus, mass coral bleaching and mortality events have significant implications for the health of the ecosystem. Given this, it is critical to monitor the spread of coral bleaching and 
understand the dynamic processes affecting the survival of coral reefs. Despite this need, direct reports of coral bleaching in the SCS have been rare, in part due to the remoteness of the region and the lack of monitoring. Mass coral bleaching was observed in areas near the Philippines such as the northern Palawan Islands $\left(11^{\circ} \mathrm{N}, 119^{\circ} \mathrm{E}\right)$ [8] and in Bolinao $\left(16^{\circ} \mathrm{N}\right.$, $119.8^{\circ} \mathrm{E}$ ) [9] during the $1998 \mathrm{El}$ Niño event. Thus, the reefs around the NS may also be susceptible to mass coral bleaching. Indeed, Yu et al. [10] documented frequent coral bleaching and mortality events in the NS during the past 200 years. These events were associated with high SSTs, including the event in 1998. The lack of information regarding bleaching events in this region hinders an evaluation of the likely responses of coral reefs to global warming and, therefore, the measures needed to protect such reefs.

We documented a coral bleaching event that occurred in June 2007 at two reefs in the NS, Meiji Reef and Zhubi Reef. We conducted in situ quantitative ecological surveys, measured zooxanthellae density, and used in situ recording and satellite remote sensing of SSTs to estimate the extent of the bleaching and the likely impact on the reefs.

\section{Materials and methods}

\subsection{Study site}

The Nansha Islands are located in the southern SCS $\left(4^{\circ}-12^{\circ} \mathrm{N}, 112^{\circ}-118^{\circ} \mathrm{E}\right)$ (Figure 1). This region is characterrized by a tropical monsoon climate. The local annual mean (2000 to 2008) SST is $28.6^{\circ} \mathrm{C}$ and ranges from $26.9^{\circ} \mathrm{C}$ (January or February) to $29.8^{\circ} \mathrm{C}$ (May or June).

We studied the corals at two ring reefs, Zhubi and Meiji Reefs (Figure 1). Zhubi Reef is a pear-shaped atoll covering an area of $\approx 16 \mathrm{~km}^{2}$ (lagoon: $\approx 7 \mathrm{~km}^{2}$ ) and having a maximum depth of $\approx 24 \mathrm{~m}$ (Figure 1A). Meiji Reef, located southeast of Zhubi Reef, is an oval-shaped atoll with an area of $\approx 46 \mathrm{~km}^{2}$ (lagoon: $\approx 36 \mathrm{~km}^{2}$ ) and a maximum depth of $\approx 30$ $\mathrm{m}$ (Figure 1B). We conducted surveys at sites on the northeast (NE) and southwest (SW) sides of Zhubi Reef (Figure $1 \mathrm{~A}$ ) and the northwest (NW), northeast (NE), and southern (S) sides of Meiji Reef (Figure 1B). The sites were chosen to ensure representation of several different habitats, including reef flats, fore-reef slopes, inner reef-slopes, and patch reefs in the lagoons.

\subsection{Ecological surveys}

We surveyed the reefs by SCUBA using manta tows, line intercept transects, and photo quadrats. At each study site, we randomly selected a quadrat $\left(50 \mathrm{~m}^{2}\right)$ and recorded and photographed the number, species, and morphology of unbleached and bleached corals in it. We calculated the percentage of bleached corals based on the ratio of bleached corals to the total number of corals.

\subsection{Coral collection and zooxanthellae density analysis}

We collected samples of unbleached and bleached corals (we collected 3-5 branches or pieces from each colony of branching and foliose corals and a $40 \mathrm{~cm}^{2}$ block from each colony of massive corals) for the analysis of zooxanthellae density and species identification [11,12]. The coral tissues were peeled from the surface of the skeleton using a WaterPik. The mixture (coral tissue and zooxanthellae in filtered seawater) was then centrifuged at $4000 \mathrm{rpm}$ for $3 \mathrm{~min}$ and the supernatant poured off. The pellet containing the

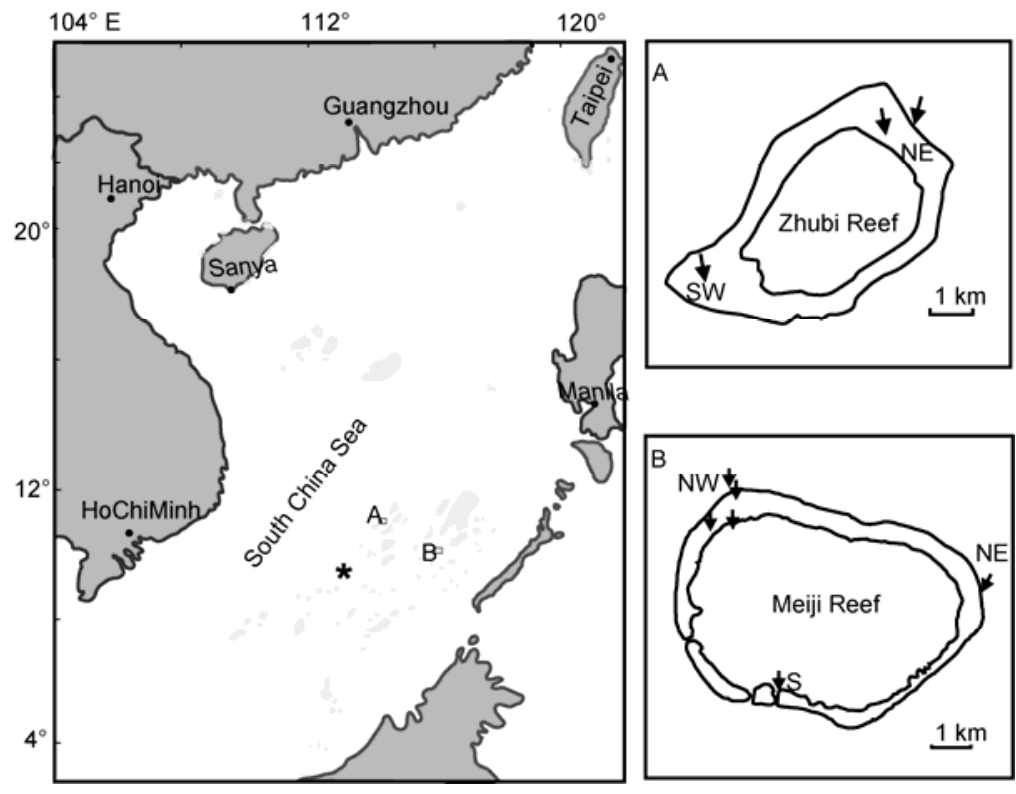

Figure 1 Map of the study sites on Zhubi (A) and Meiji (B) reefs, Nansha Islands (modified from Yu and Zhao [7]). 
zooxanthellae was fixed with $1 \mathrm{~mL} 10 \%$ formalin and held at $0^{\circ} \mathrm{C}$ for $2-4 \mathrm{~h}$.

We counted the number of zooxanthellae in a sample using a hemocytometer then expanded the count to the total number of zooxanthellae $(A)$. We calculated the surface area of the coral skeleton $(S)$ using the relationship between the weight and surface area of the aluminum foil used for wrapping the coral skeletons. We then calculated the density of symbiotic zooxanthellae $(d)$ using the relationship between the number of zooxanthellae and surface area of the aluminum foil as follows: $d\left(\right.$ cell $\left./ \mathrm{cm}^{2}\right)=A / S$.

\subsection{SST data collection}

We used in situ mean monthly SSTs (recorded at the adjacent Yongshu Reef, * in Figure 1) and SSTs derived from remote sensing (NOAA coral reef survey detection satellite, resolution $\left.=0.5^{\circ} \times 0.5^{\circ}\right)$ data to model SST anomalies in the NS.

\section{Results and discussion}

\subsection{Bleached species and distribution}

We observed bleaching in 11 and 26 coral species at Zhubi and Meiji reefs, respectively (Table 1). A high percentage of corals $(30 \%, 12$ of 40) were bleached on Zhubi Reef. Similarly, we observed severe coral bleaching at the reef flat site in the northwest section of Meiji Reef (NW, Figure 1B). Of the 180 corals we examined at this site, $27 \%$ were bleached. These were primarily found in the surface waters ( $<5 \mathrm{~m}$ depth). The bleached coral species included Acropora, Stylophora, Astreopora, Porites, Goniastrea, Cyphastrea, and Fungia. The corals were sparsely distributed on the inner reef-slope (NW) of Meiji Reef and there was a lower incidence of bleaching at this site $(18 \%, 9$ of 50 corals). The most abundant coral communities ( $>90 \%$ coral cover) were located on the outside reef slope (NW, Figure $1 \mathrm{~B})$. This site also had the lowest incidence of bleaching $(\approx 6 \%)$. Of the 305 corals we examined at this site, only 17 were bleached and these were primarily located within $20 \mathrm{~m}$ of the surface. The bleached species included Helioporacea, Seriatopora, Milleporina, Pocillopora, Acropora, and Goniastrea. We observed bleaching in 18 of 95 corals (18.9\%) on the southern end of Meiji Reef (S, Figure 1B). These were primarily distributed within $5 \mathrm{~m}$ depth, although the bleached Acropora corals were also found up to depths of $20 \mathrm{~m}$. The bleached species included Acropora, Montipora, Goniastrea, Favia, and Porites. In general, the bleached

Table 1 Species-dependent coral bleaching on Zhubi and Meiji Reef, Nansha Islands

\begin{tabular}{|c|c|c|c|}
\hline \multirow{2}{*}{ Family } & \multirow{2}{*}{ Genera } & \multicolumn{2}{|c|}{ Species } \\
\hline & & Meiji Reef & Zhubi Reef \\
\hline \multirow[t]{13}{*}{ Acroporidae } & Astreopora & Astreopora myriophthalma & \\
\hline & Montipora & Montipora efflorescens & \\
\hline & & Montipora digitata & \\
\hline & Acropora & Acropora valida & Acropora hyacinthus \\
\hline & & Acropora palifera & Acropora cerealis \\
\hline & & Acropora nasuta & Acropora digitifera \\
\hline & & Acropora formosa & Acropora gemmifera \\
\hline & & Acropora hyacinthus & Acropora prostrata \\
\hline & & Acropora aspera & \\
\hline & & Acropora brueggemanni & \\
\hline & & Acropora grandis & \\
\hline & & Acropora nobilis & \\
\hline & & Acropora teres & \\
\hline \multirow[t]{3}{*}{ Pocilloporidae } & Seriatopora & Seriatopora hystrix & \\
\hline & Pocillopora & Pocillopora verrucosa & Pocillopora verrucosa \\
\hline & Stylophora & Stylophora pistillata & \\
\hline \multirow[t]{6}{*}{ Faviidae } & Cyphastrea & Cyphastrea microphthalma & \\
\hline & Favia & Favia rotumana & \\
\hline & Favites & Favites bestae & \\
\hline & Goniastrea & Goniastrea aspera & \\
\hline & & Goniastrea ednardsi & \\
\hline & & Goniopora somdiensis & \\
\hline Fungiidae & Fungia & Ctenactis crassa & Fungia echinata \\
\hline \multirow[t]{2}{*}{ Poritidae } & Porites & Porites lutea & Porites solida \\
\hline & & & Porites pukoensis \\
\hline Helioporacea & Helioporacea & Helioporacea & \\
\hline Milleporina & Milleporina & Milleporina & \\
\hline
\end{tabular}


corals were primarily distributed in shallow waters $(<5 \mathrm{~m})$ along the inner slope and on the patch reefs in the lagoons of both reefs.

The branching corals appeared to be the most vulnerable to bleaching (Figure 2). However, we also observed bleaching in some small massive corals (e.g. Porites) that were thought to be resistant to thermal stress (Figure 2(d)). Furthermore, a number of large Acropora corals appeared pale (Figure 2(e)), indicating that they were in the early stages of bleaching. We estimated that these small bleached corals were $\approx 10$ years old and had begun growing in 1998 .

\subsection{Zooxanthellae density indicates the degree of coral bleaching}

Coral bleaching is defined as the loss of the symbiotic zooxanthellae from a host coral. Thus, zooxanthellae density can be used as a direct indicator for estimating the degree of coral bleaching. The mean zooxanthellae density for Acropora spp. and Pocillopora spp. was $0.26 \times 10^{6}$ and $0.17 \times 10^{6} \mathrm{cell} / \mathrm{cm}^{2}$, respectively (Figure 3 ). This is equal to, or slightly lower, than the values reported in bleached corals from other areas, such as Moorea Island in French Polynesia [13]. At this site, bleached Acropora and Pocillopora corals contained $0.28 \times 10^{6}$ and $0.30 \times 10^{6} \mathrm{cell} / \mathrm{cm}^{2}$ zooxanthellae, respectively. Corals from the NS that had no visual signs of bleaching also had low levels of zooxanthellae density (Figure 3). For example, the Acropora corals contained $0.7 \times 10^{6} \mathrm{cell} / \mathrm{cm}^{2}$ of zooxanthellae, which is lower than the values commonly reported in other regions $\left(1 \times 10^{6}\right.$ to $2 \times 10^{6}$ cell $/ \mathrm{cm}^{2}$ ) [12,14-16].

The density of zooxanthellae in corals collected at Meiji and Zhubi Reef was significantly lower than in corals collected in the same season (May 2007) at Sanya (Figure 1), an area where environmental conditions are favorable for coral growth (Figure 3). For example, bleached Acropora, Pocillopora, Porites, and Favia corals had lost nearly 90\%, $89 \%, 72 \%$, and $84 \%$ of their zooxanthellae, respectively. Interestingly, even the corals that had no visual signs of bleaching had also lost $48 \%, 53 \%, 45 \%$, and $31 \%$ of their zooxanthellae, suggesting that they were in the initial stages of bleaching. Interestingly, the Agariciidae corals appeared to retain the majority of their symbiotic zooxanthellae. The loss of zooxanthellae in the NS corals was similar to that reported in other areas, including Phuket, southern Thailand [17] and Lakshadweep Kavaratti, India [18].

\subsection{Species-dependent susceptibility to bleaching}

The mean proportion of bleached corals (the ratio of
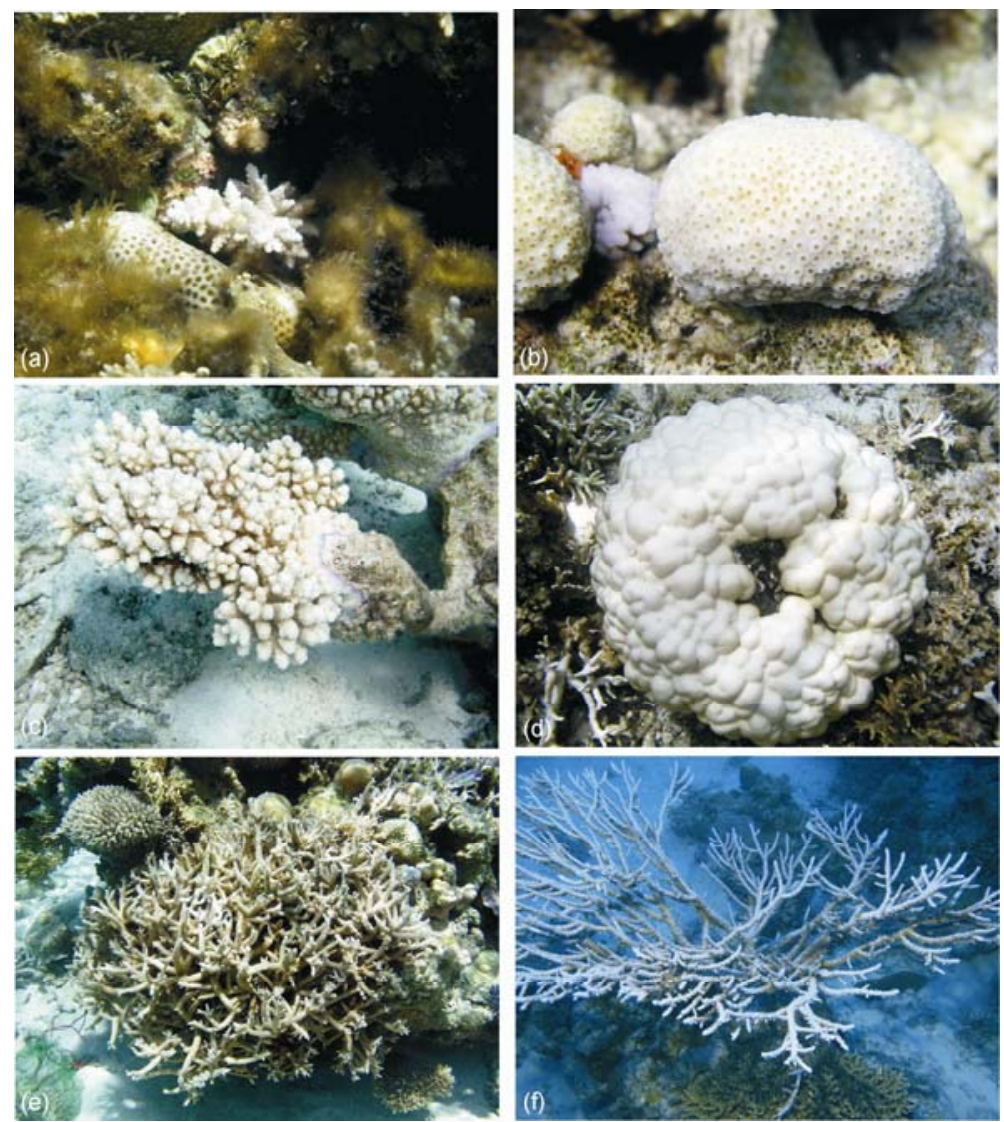

Figure 2 Bleached corals found at Meiji Reef. (a) Acropora and Favia; (b) Plesiastrea and Pocillopora; (c) Acropora; (d) Porites; (e) Acropora; (f) Acropora. 


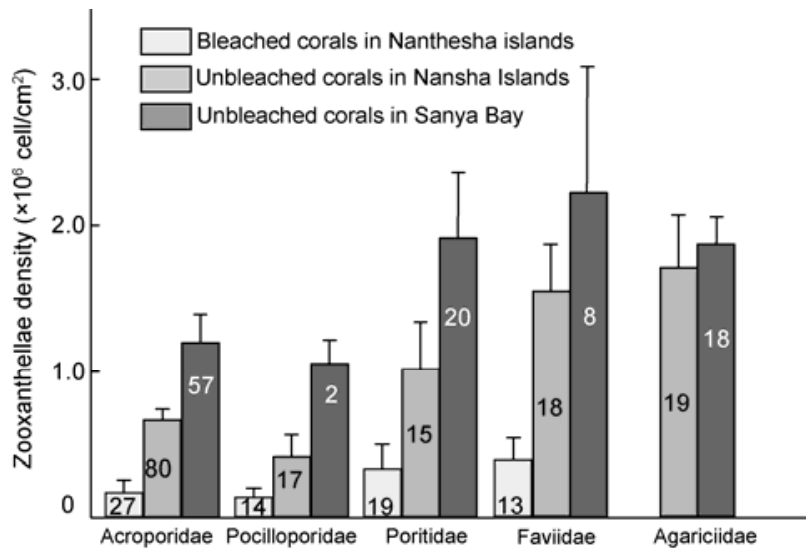

Figure 3 Mean density of symbiotic zooxanthellae (Numbers in the histograms represent the number of coral samples, mean $\pm \mathrm{SE}$ ).

bleached corals to total corals) was $15.6 \%$ at Meiji Reef. The incidence of bleaching was highest for the Pocillopora corals (23\%) followed by Acoropora (21\%), Favia $(<10 \%)$, and Porites $(<10 \%)$ (Figure 4$)$. The branching (Pocillopora and Acropora) corals were the most vulnerable in the NS. The massive corals (Favia, Porites, and Fungia) appeared to be more resistant to bleaching. We did not observe bleaching in any Agariciidae corals, suggesting that this family of corals may have the highest resistance to thermal stresses in the NS. Our results are consistent with previous observations in our laboratory $[19,20]$ which also suggested that branching Acropora corals were the most susceptible to changes in SSTs, followed by massive Porites corals. Similarly, our laboratory studies demonstrated that Pavona spp. (Agariciidae) had the highest resistance to thermal stress. Taken together, these observations suggest that Agariciidae may become the dominant species in the SCS based on the projected impacts of global warming.

Our results are also consistent with studies in other seas. For example, Stimson et al. [14] concluded that the relative

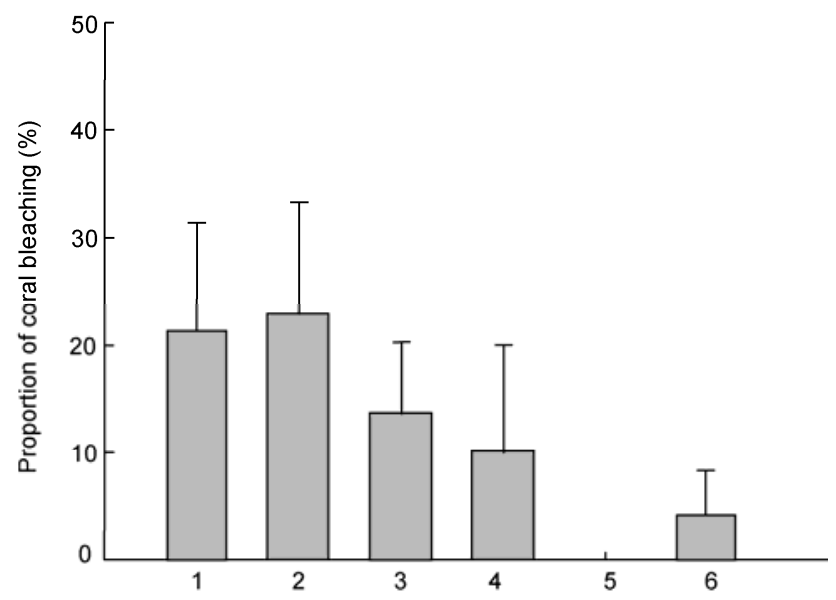

Figure 4 Distribution of bleached coral species at Meiji Reef (values represent the mean \pm SE). 1, Acroporidae; 2, Pocilloporidae; 3, Faviidae; 4, Poritidae; 5, Agariciidae; 6, Fungiidae. order of susceptibility for corals was: Acropora $>$ Seriatopora $>$ Pocillopora $>$ Montipora $>$ Helioporacea $>$ Favia $>$ Porites, suggesting that Acropora and Pocillopora corals were the most susceptible to bleaching. Similarly, Loya et al. [21] also reported significant mortality in the branching corals Acropora and Pocillopora during the 1998 bleaching event in Japan. Edwards et al. [22] reported bleaching in 98\% of Acropora and Pocillopora corals in the Maldives in 1998, whereas the massive corals (e.g. Porites, Favia, and Agariciidae) did not suffer bleaching.

The susceptibility of corals to bleaching may be related to their morphology and zooxanthellae density [12]. The massive corals such as Porites and Favia contained more zooxanthellae and survived better in mass bleaching events whereas coral species that contain less zooxanthellae, such as Acropora. and Pocillopora, sometimes suffered serious bleaching (Figure 3).

\subsection{Abnormally high temperatures caused coral bleaching}

The monthly mean SST in June $2007\left(30.8^{\circ} \mathrm{C}\right)$ was the highest since 1998 (Figure 5). Furthermore, the rate of increase in SSTs in the first half of 2007 (up to $0.848^{\circ} \mathrm{C} /$ month) was higher than the mean values $\left(0.651^{\circ} \mathrm{C} /\right.$ month $)$ during the most recent 12 years (1997-2008). SSTs decreased sharply following the anomaly which, when combined with relative low insolation, was theoretically favorable for the recovery of coral reefs from bleaching. The SSTs increased slowly in the first half of the year in 1998, but then remained higher $\left(>30.8^{\circ} \mathrm{C}\right)$ than normal $\left(30.3^{\circ} \mathrm{C}\right)$ for a prolonged period (May, June, July, and August) [23]. Thus, SSTs were sufficiently elevated for a long enough period to cause mass coral bleaching and mortality in the NS in 1998. Many of the small coral colonies $(<10$ years old) found in our survey appear to have begun growing following this mass coral bleaching event.

NOAA Hotspots revealed abnormalities in SSTs (ranging from $0.5-1.0^{\circ} \mathrm{C}$ ) near the NS after May 21, 2007. The differences were centered in the southeast region of the SCS $\left(12^{\circ} \mathrm{N}, 118^{\circ} \mathrm{E}\right)$, very close to our study sites (Figure 6$)$. On June 28 , the anomaly value was between 0.75 and $1^{\circ} \mathrm{C}$. Our

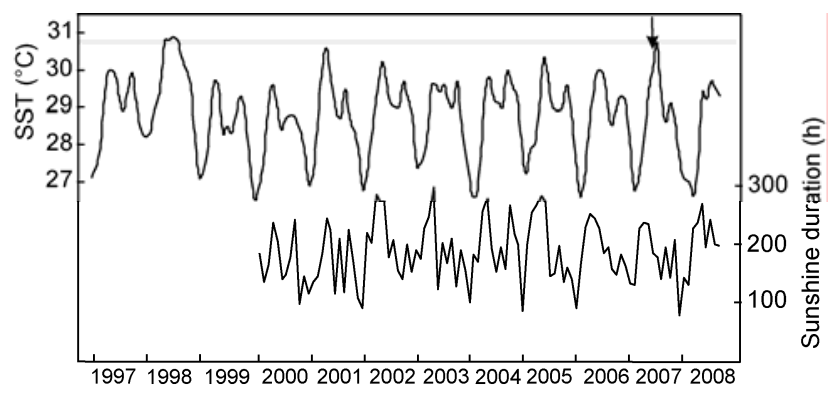

Figure 5 Monthly SST and duration of sunlight on the Nansha Islands (Data were recorded at the Yongshu Observation Station). 

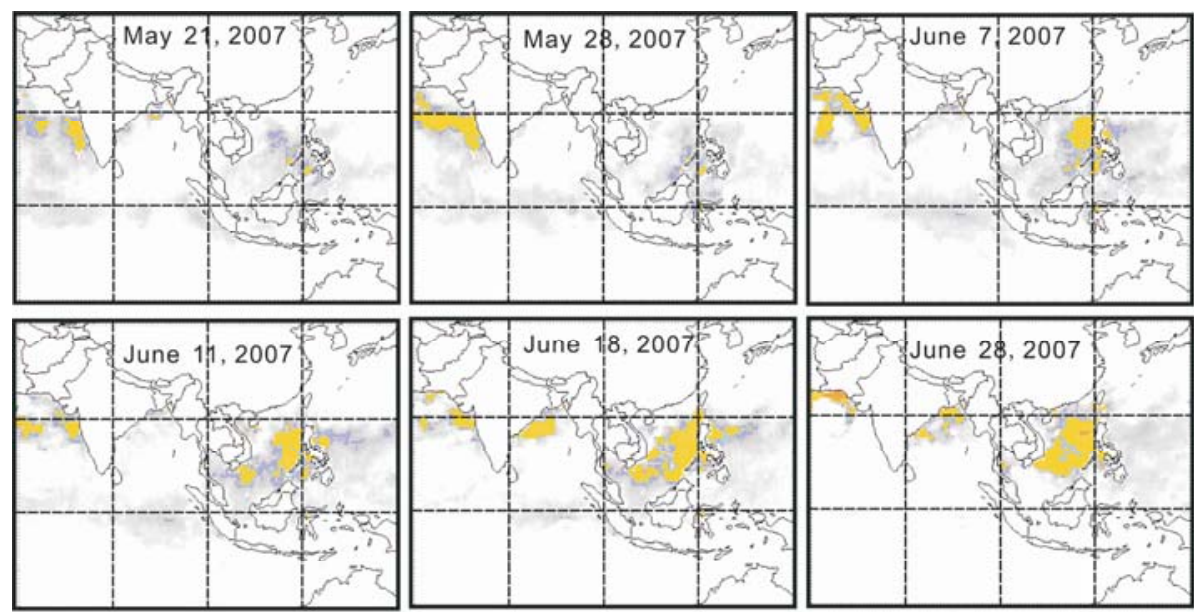

0.000 .250 .500 .751 .001 .251 .501 .752 .002 .252 .502 .753 .003 .253 .503 .754 .004 .254 .504 .755 .00

Figure 6 Hotspots variation during 2007 in the South China Sea (the yellow patterns mapped the SST anomaly, http://www.osdpd.noaa.gov/ml/ocean/ cb/hotspots.html).

sampling and survey time (June 6-19) overlapped with the beginning of this abnormality. Although we noted bleaching in a number of corals, others displayed no visual signs of bleaching yet had low levels of zooxanthellae (Figure 3) indicating that our surveys may have only captured the initial stages of this coral bleaching event. Thus, the intensity of the event may have increased following our surveys (e.g. in July or August).

Liu et al. [24] suggested that DHW (Degree Heating Weeks) may be used to supplement Hotspots data and improve the ability to predict the occurrence of coral bleaching. The DHW values during the period covered in the current study were less than $3^{\circ} \mathrm{C} /$ week (Figure 7, blue patterns) in the NS, suggesting that the accumulated thermal stress was insufficient to cause ecologically significant levels of bleaching [24]. However, given that we documented the occurrence of coral bleaching on Zhubi and Meiji reefs, predictions based on HotSpots and DHW may be conservative when assessing the risk of bleaching [25].

The hot water column continuing expanding into the northern SCS during mid-July, 2007 (Figure 7) causing widespread bleaching of corals in Kenting, southern Taiwan. This event affected $\approx 45$ species of stony corals and was the most severe coral bleaching event since 1998 [26]. Furthermore, relatively high-latitude regions such as Iki, Miyako and the Ishigaki Islands in Japan experienced a series of moderate to severe coral bleaching events [26]. However, the DHW (July 16) index for this period suggested that the cumulative thermal stress in Taiwan was not sufficient to cause widespread coral bleaching (Figure 7), confirming our hypothesis that satellite remote sensing may underestimate the risk of coral bleaching in the NS.

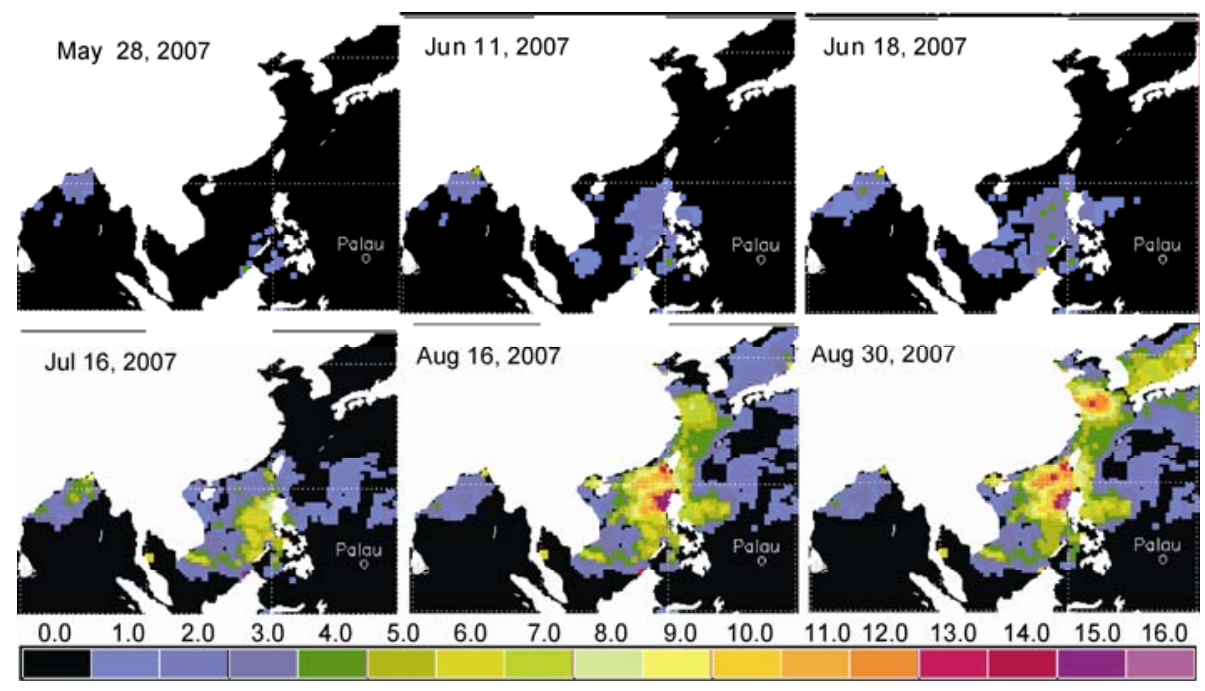

Figure 7 DHW values in the Nansha Islands. DHW measures accumulated thermal stress over the past 12 weeks by summing any Hotspots at or above $1^{\circ} \mathrm{C}$ and expressing them in units of ${ }^{\circ} \mathrm{C}$-weeks. The data are available online at http://www.osdpd.noaa.gov/ml/ocean/cb/dhw_2007.html. A DHW of $4^{\circ} \mathrm{C}$-weeks represents enough accumulated thermal stress to cause ecologically significant bleaching and a $\mathrm{DHW}$ of $8^{\circ} \mathrm{C}$-weeks indicates that widespread bleaching and mortality are likely [24]. 


\section{Conclusions}

Based on ecological surveys at Zhubi and Meiji Reefs of Nansha Islands, analysis of symbiotic zooxanthellae density in both bleached and (apparently) unbleached corals, and measurements of SST from both the Ocean Observatory and satellite remote sensing records, we conclude that the coral reefs in the Nansha Islands were experiencing the early stages of bleaching between June and July, 2007. At least 35 coral species at depths of 0 to $20 \mathrm{~m}$ were bleached during this event. The branching corals Pocillopora and Acropora were the most vulnerable to bleaching whereas the massive corals Porites and Favia were more tolerant. Surprisingly, we did not observe bleaching in any Agariciidae corals suggesting that these species were highly resistant to thermal stresses. Although the monthly mean SST was $\approx 30.8^{\circ} \mathrm{C}$ during this period, the damage to the coral reefs is predicated to be lower than in 1998, because of SSTs were elevated for a shorter period. Our results suggest that the coral reefs in NS are highly susceptible to bleaching, particularly when viewed in light of the projected impacts of global warming.

We are grateful to Wang Rong for his help in the field. This work was supported by the National Natural Science Foundation of China (40830852 and 41025007), the Chinese Ministry of Science \& Technology Program (2007CB815905 and 2006BAB19B03) and an ARC discovery grant (DP0773081).

1 Li S, Yu K F. Recent development in coral reef bleaching research (in Chinese). Acta Ecol Sin, 2007, 27: 2059-2069

2 Hoegh-Guldberg O. Climate change, coral bleaching and the future of the world's coral reefs. Mar Freshwater Res, 1999, 50: 839-866

3 Baker A, Glynn P, Riegl B. Climate change and coral reef bleaching: An ecological assessment of long-term impacts, recovery trends and future outlook. Est Coast Shelf Sci, 2008, 80: 435-471

4 Wilkinson C. Status of coral reefs of the world: 2002. Townsville: Global Coral Reef Monitoring Network and Reef and Rainforest Research Centre, 2002. 1-377

5 Carpenter K, Abrar M, Aeby G, et al. One-third of reef-building corals face elevated extinction risk from climate change and local impacts. Science, 2008, 321: 560-563

6 Wilkinson C. Status of coral reefs of the world: 2008. Townsville: Global Coral Reef Monitoring Network and Reef and Rainforest Research Centre, 2008. 1-296

7 Yu K F, Zhao J X. Coral Reefs. In: Wang P X, Li Q Y. The South China Sea Paleoceanography and Sedimentology. Berlin: Springer, 2009. 229-254

8 Arceo H O, Quibilan M C, Alino P M, et al. Coral bleaching in Philippine reefs: Coincident evidences with mesoscale thermal anomalies. Bull Mar Sci, 2001, 69: 579-593
9 Cesar H, Pet-Soede L, Quibilan M C C, et al. First evaluation of the impacts of the 1998 coral bleaching event to fisheries and tourism in the Philippines. In: Schuttenberg H Z, ed. Coral Bleaching: Assessing and Linking Ecological and Socioeconomic Impacts, Future Trends and Mitigation Planning. Kingston: University of Rhode Island, 2000. 41-58

10 Yu K F, Zhao J X, Shi Q, et al. U-series dating of dead Porites corals in the South China sea: Evidence for episodic coral mortality over the past two centuries. Quat Geochronol, 2006, 1: 129-141

11 Johannes R E, Wiebe W J. Method for determination of coral tissue biomass and composition. Limnol Oceanogr, 1970, 15: 822-824

12 Li S, Yu K F, Shi Q, et al. Interspecies and spatial diversity in the symbiotic zooxanthellae density in corals from northern South China Sea and its relationship to coral reef bleaching. Chinese Sci Bull. 2008, 53: 295-303

13 Hoegh-Guldberg O, Salvat B. Periodic mass-bleaching and elevated sea temperatures: Bleaching of outer reef slope communities in Moorea, French Polynesia. Mar Ecol Prog Ser, 1995, 121: 181-190

14 Stimson J, Sakai K, Sembali H. Interspecific comparison of the symbiotic relationship in corals with high and low rates of bleaching-induced mortality. Coral Reefs, 2002, 21: 409-421

15 Costa C F, Sassi R, Amaral F D. Annual cycle of symbiotic dinoflagellates from three species of scleractinian corals from coastal reefs of northeastern Brazil. Coral Reefs, 2005, 24: 191-193

16 Fagoonee I, Wilson H B, Hassell M P, et al. The dynamics of zooxanthellae populations: A long-term study in the field. Science, 1999, 283: 843-845

17 Brown B E, Letissier M D A, Bythell J C. Mechanisms of bleaching deduced from histological studies of reef corals sampled during a natural bleaching event. Mar Biol, 1995, 122: 655-663

18 Harithsa S, Raghukumar C, Dalal S. Stress response of two coral species in the Kavaratti atoll of the Lakshadweep Archipelago, India. Coral reefs, 2005, 24: 463-474

19 Li S, Yu K F, Shi Q, et al. Low water temperature tolerance and responding mode of scleractinian corals in Sanya Bay (in Chinese). Chin J Appl Ecol, 2009, 20: 2289-2295

20 Li S, Yu K F, Shi Q. Experimental study of stony coral response to the high temperature in Luhuitou of Hainan Island (in Chinese). Trop Geogr, 2008, 28: 534-539

21 Loya Y, Sakai K, Yamazato K, et al. Coral bleaching: The winners and the losers. Ecol Lett, 2001, 4: 122-131

22 Edwards A J, Clark S, Zahir H, et al. Coral bleaching and mortality on artificial and natural reefs in Maldives in 1998, sea surface temperature anomalies and initial recovery. Mar Pollut Bull, 2001, 42: $7-15$

23 Lough J M. 1997-98: Unprecedented thermal stress to coral reefs? Geophys Res Lett, 2000, 27: 3901-3904

24 Liu G, Strong A E, Skirving W. Overview of NOAA coral reef watch program's near-real time satellite global coral bleaching monitoring activities. Proc 10th Int Coral Reef Symp. 2005, 1: 1783-1793

25 McClanahan T R, Ateweberhan M, Sebastian C R, et al. Predictability of coral bleaching from synoptic satellite and in situ temperature observations. Coral Reefs, 2007, 26: 695-701

26 Kimura T, Dai C F, Park H S. Status of Coral Reef Resources in East and North Asia (China, Hong Kong, Taiwan, South Korea and Japan). In: Wilkinson C, eds. Status of Coral Reefs of the World: Townsville: Global Coral Reef Monitoring Network and Reef and Rainforest Research Center, 2008. 145-158

Open Access This article is distributed under the terms of the Creative Commons Attribution License which permits any use, distribution, and reproduction in any medium, provided the original author(s) and source are credited. 